\title{
腸内細菌叢に影響する薬剤と漢方薬の併用実態調査
}

\author{
石原三也, ${ }^{a}$ 本間真人, ${ }^{*}, a, b$ 久能英子, ${ }^{a}$ 渡邊真知子, ${ }^{c}$ 幸田幸直 $a, b$
}

\section{Combination Use of Kampo-Medicines and Drugs Affecting Intestinal Bacterial Flora}

\author{
Miya Ishihara, ${ }^{a}$ Masato Homma, ${ }^{* a, b}$ Eiko KunO, ${ }^{a}$ \\ Machiko WatANABE, ${ }^{c}$ and Yukinao KoHDA ${ }^{a, b}$ \\ Department of Pharmacy, Tsukuba University Hospital, ${ }^{a}$ 2-1-1, Amakubo, Tsukuba, Ibaraki \\ 305-8576, Japan, Department of Pharmaceutical Sciences, Institute of Clinical Medicine, \\ University of Tsukuba, ${ }^{b}$ 1-1-1, Ten-nodai, Tsukuba, Ibaraki 305-8575, Japan, and \\ Faculty of Pharmaceutical Sciences, Teikyo University, ${ }^{c} 1091-1$, \\ Suarashi, Sagamiko, Tsukui-gun, Kanagawa 199-0195, Japan
}

(Received April 19, 2002; Accepted June 20, 2002)

\begin{abstract}
The intestinal bacteria, Eubacterium sp. and Bifidobacterium sp., participate in the metabolism of active kampo-ingredients, glycyrrhizin (GL), sennoside (SEN) and baicalin (BL). Since antibiotics and bacterial preparations, Bifidobacterium longum $\left(\mathrm{LAC}-\mathrm{B}^{\circledR}\right)$, Clostridium butyricum $\left(\mathrm{MIYA}^{-} \mathrm{BM}^{\circledR}\right)$, and Streptococcus faecalis (BIOFERMIN $^{\circledR}$ ), affect the bacterial population in intestinal bacterial flora, metabolism of the active kampo-ingredients in the bacterial flora may be altered by their combined administration. We investigated 1199 prescriptions including kampo-medicines for 308 patients. Combination use of kampo-medicines with antibiotics and bacterial preparations occurred with $7 \%$ and $10 \%$ of the kampo-prescription, respectively. Most antibiotics have activity against intestinal bacteria, except that cephems and macrolides are not active against to $E$. coli. This means that antibiotics may lower the metabolism of GL, SEN and BL when administered in combination. On the other hand, it is also highly possible that bacterial preparations increase the number of Eubacterium $s p$. and Bifidobacterium sp., resulting in enhanced metabolism of GL and SEN when they are used concomitantly with kampo-medicines. The present results suggested that the drug interactions of kampo-medicines with antibiotics and bacterial preparations should be confirmed in clinical studies.
\end{abstract}

Key words_ — kampo-medicines; intestinal bacterial flora; drug interaction; antibiotics; bacterial preparations

\section{は じめに}

漢方有効成分の代謝において, 腸内細菌叢の関与 が明らかになってきた（Table 1)。例えば，甘草の グリチルリチン（GL）は，腸内細菌のEubacteri$u m$ 属の $\beta$-グルクロニダーゼによりグリチルレチン 酸（GA）に代謝された後, 体内に吸収される. ${ }^{1,2}$ 大黄又はセンナのセンノシド（SEN）は, 腸内細 菌の Bifidobacterium 属の $\beta$-グルコシダーゼにより セニジンに代謝され，さらにPeptostreptococcus 属 の還元酵素によりレインアンスロンに代謝され, 活 性本体となる. ${ }^{1,2}$ 黄芩のバイカリン（BL）は，腸内

a) 筑波大学附属病院薬剂部, b) 筑波大学臨床医学系臨床 薬剤学, ${ }^{c}$ 帝京大学薬学部臨床薬学

e-mail: masatoh@mail.hosp.tsukuba.ac.jp
細菌の Streptococcus 属とE. coli の $\beta$-グルクロニ ダーゼによりバイカレイン（BA）に代謝され，小 腸上皮細胞へ吸収された後, 細胞内で再び抱合され BL として血中に移行する. ${ }^{1,2)}$ このように, 漢方有 効成分の代謝には腸内細菌叢による代謝変換が大き く影響すると考えられる。

抗生物質は腸内細菌の増殖を抑制し, ${ }^{3,4)}$ 生菌製剂 は腸内細菌叢に変化をもたらす5-8)ため, これらの 併用は漢方有効成分の代謝に影響を与えることが考 えられる. しかし, このような視点で薬物相互作用 が研究されたことはこれまでにない。今回, 我々 は, 漢方薬と抗生物質又は生菌製剤の併用実態を調 査し，それらが漢方有効成分の代謝に及ぼす影響を 考察したので報告する. 
Table 1. Biotransformation of Kampo-Ingredients by Intestinal Bacteria

\begin{tabular}{|c|c|c|c|c|}
\hline Herbs & Active ingredients & Metabolites & Intestinal bacteria & Enzyme \\
\hline \multirow[t]{2}{*}{ Aloe } & Aloesin, Aloeresin $\mathrm{A}^{1)}$ & Aloesone & - & glucosidase \\
\hline & Barbaloin $^{1)}$ & Aloe-emodin anthrone & Eubacterium & glucosidase \\
\hline Aconiti Tuber & Aconitine $^{1)}$ & Lipoaconitine & $\begin{array}{l}\text { Bacteroides, Clostridi- } \\
\text { um, Klebsiella }\end{array}$ & - \\
\hline $\begin{array}{l}\text { Anemarrhenae Rhizo- } \\
\text { ma }\end{array}$ & Mangiferin $^{1)}$ & Northyriol & - & glucosidase \\
\hline Aristolochiae Fructus & Aristolochic acid ${ }^{1)}$ & $\begin{array}{l}N \text {-Hydroxyaristolac- } \\
\text { tam, Aristolactam }\end{array}$ & - & - \\
\hline Bupleuri Radix & Saikosaponin $^{2)}$ & Saikogenin & - & - \\
\hline Carthami Flos & Safflor yellow $\mathrm{B}^{1)}$ & $\begin{array}{l}\text { Carthamin, Hydroxy- } \\
\text { safflor yellow A }\end{array}$ & - & - \\
\hline \multirow[t]{2}{*}{ Gardeniae Fructus } & Geniposide $^{1)}$ & Genipin & Eubacterium & $\beta$-glucosidase \\
\hline & Gardenoside $^{1)}$ & Gardenogenin & - & $\beta$-glucosidase \\
\hline${ }^{\dagger}$ Glycyrrhizae Radix & Glycyrrhizin $^{1)}$ & Glycyrrhetic acid & ${ }^{*}$ Eubacterium & $\beta$-glucuronidase \\
\hline Ginseng Radix & Ginsenoside $^{2)}$ & Protopanaxadiol & Eubacterium & $\beta$-glucosidase \\
\hline Magnoliae Cortex & Magnolol' $^{2)}$ & Isomagnolol & - & - \\
\hline \multirow[t]{2}{*}{ Paeoniae Radix } & Albiflorin ${ }^{2)}$ & Albimetabolin & - & - \\
\hline & Paeoniflorin ${ }^{1)}$ & Paeonimetabolin I, II & $\begin{array}{l}\text { Bacteroides, Lac- } \\
\text { tobacillus }\end{array}$ & $\beta$-glucosidase, esterase \\
\hline Plantaginis Semen & Aucubin $^{1)}$ & Aucubigenin & $\begin{array}{l}\text { Bacteroides, Bifidobac- } \\
\text { terium }\end{array}$ & - \\
\hline \multirow{2}{*}{$\begin{array}{l}\text { 'Rhei Rhizoma, Sennae } \\
\text { Folium }\end{array}$} & Sennoside ${ }^{1)}$ & Sennidin & *Bifidobacterium & $\beta$-glucosidase \\
\hline & Sennidin $^{1)}$ & Rheinanthrone & ${ }^{*}$ Peptostreptococcus & reductase \\
\hline${ }^{\dagger}$ Scutellariae Radix & Baicalin $^{1)}$ & Baicalein & $\begin{array}{l}{ }^{*} \text { E. coli, }{ }^{*} \text { Streptococ- } \\
\text { cus }\end{array}$ & $\beta$-glucuronidase \\
\hline Sophorae Flos & Rutin ${ }^{2)}$ & Quercetin & $\begin{array}{l}\text { Bacteroides, Strep- } \\
\text { tococcus }\end{array}$ & $\beta$-glucosidase \\
\hline \multirow[t]{2}{*}{ Swertiae Herba } & Homoorientin ${ }^{1)}$ & Luteolin, Eriodictyol & - & glucosidase \\
\hline & Swertiamarin ${ }^{1)}$ & $\begin{array}{l}\text { Erythrocentaurin, Gen- } \\
\text { tianine }\end{array}$ & - & $\beta$-glucosidase \\
\hline
\end{tabular}

†: Target herbs of the present study, *: Target bacteria of the present study.

\section{方法}

筑波大学附属病院において, 2001 年 1 月から 4 月までの 4 カ月間に，甘草，黄芩，大黄のいずれか を含む漢方薬（十全大補湯，大黄甘草湯，柴苓湯， 補中益気湯, 柴胡桂枝湯, 小柴胡湯, 大柴胡湯, 六 君子湯，柴胡加竜骨牡蚛湯，人参養栄湯，人参湯， 温清飲, 温経湯, 柴朴湯, 黄連解毒湯, 茵蔯高湯) が処方された入院・外来処方箋 1199 枚（患者数 308 名）について，抗生物質又は生菌製剂の併用実 態を調査した.

また，実際に併用されていた抗生物質や生菌製剤 の Eubacterium 属, Bifidobacterium 属, Peptostreptococcus 属, Streptococcus 属, E. coli に及ぼす影 響を文献調査した. ${ }^{5-50)}$ 各抗生物質の抗菌活性は, 金沢らの方法 ${ }^{51)}$ に準じ，最小発育阻止濃度（MIC）
から，耐性 ( - ), やや感受性 $(+)$, 高感受性 $(++)$ の 3 段階に分類して評価した.

\section{結果}

1. 漢方薬と抗生物質の併用実態 調査処方箋 1199 枚（患者数 308 名）のうち，84 枚（7\%）に抗 生物質が併用処方されていた。 Table 2 に漢方薬と 併用処方された抗生物質の内訳を示した. Cephem (CEP) 系抗生物質 31 枚, quinolone (QL) 系 20 枚, macrolide (ML) 系 17 枚, penicilline (PC) 系 10 枚, penem (PN) 系 3 枚, aminoglycoside (AG) 系 1 枚, tetracycline（TC）系 1 枚, ST 合剂 （ST） 1 枚において併用処方されていた。抗生物質 と併用されていた漢方薬は 9 種類であった。最も多 く併用された漢方薬は, 補中益気湯の 23 枚であ り, 次いで, 柴苓湯 19 枚, 十全大補湯・大黄甘草 
Table 2. Combination Use of Kampo-Medicine and Antibiotics

\begin{tabular}{|c|c|c|c|c|c|c|c|c|c|}
\hline \multirow{2}{*}{ Kampo-prescription } & \multicolumn{9}{|c|}{ Number of prescriptions } \\
\hline & (n) & CEP & QL & ML & $\mathrm{PC}$ & $\mathrm{PN}$ & $\mathrm{AG}$ & $\mathrm{TC}$ & ST \\
\hline Hochu-ekki-to & 23 & 13 & 5 & 5 & & & & & \\
\hline Sairei-to & 19 & 4 & 1 & 4 & 7 & & 1 & 1 & 1 \\
\hline Juzen-taiho-to & 9 & 1 & 1 & 4 & 1 & 2 & & & \\
\hline Daio-kanzo-to & 9 & 5 & 4 & & & & & & \\
\hline Saiko-keishi-to & 8 & 3 & 2 & & 2 & 1 & & & \\
\hline Rikkunshi-to & 8 & 3 & 1 & 4 & & & & & \\
\hline Sho-saiko-to & 6 & 1 & 5 & & & & & & \\
\hline Dai-saiko-to & 1 & & 1 & & & & & & \\
\hline Unsei-in & 1 & 1 & & & & & & & \\
\hline Total & 84 & 31 & 20 & 17 & 10 & 3 & 1 & 1 & 1 \\
\hline
\end{tabular}

CEP: cephem, QL: quinolone, ML: macrolide, PC: penicilline, PN: penem, AG: aminoglycoside, TC: tetracycline, ST: sulfamethoxazole trimethoprim.

Table 3. Effects of Antibiotics on Bacteria, Eubacterium sp., Bifidobacterium sp., Peptostreptococcus sp., Streptococcus sp., E. coli

\begin{tabular}{|c|c|c|c|c|c|c|}
\hline \multirow{2}{*}{\multicolumn{2}{|c|}{ Antibiotics }} & \multicolumn{5}{|c|}{ Bacteria } \\
\hline & & \multirow{2}{*}{$\begin{array}{c}\text { Eubacterium } s p . \\
+\sim+\end{array}$} & \multirow{2}{*}{$\begin{array}{c}\text { Bifidobacterium } s p . \\
+\sim+\end{array}$} & \multirow{2}{*}{$\begin{array}{c}\text { Peptostreptococcus sp. } \\
-\sim+\end{array}$} & \multirow{2}{*}{$\begin{array}{c}\text { Streptococcus sp. } \\
-\sim H\end{array}$} & \multirow{2}{*}{$\begin{array}{l}\text { E. coli } \\
-\sim H\end{array}$} \\
\hline CEP & $\mathrm{CCL}$ & & & & & \\
\hline & CFIX & ne & ne & $+\sim H$ & - & $H$ \\
\hline & CFDN & $+\sim H$ & $H$ & $+\sim H$ & + & $H$ \\
\hline & CFTM-PI & $-\sim H$ & ne & H & $-\sim H$ & $-\sim H$ \\
\hline & CPDX-PR & H & ne & $+\sim H$ & $-\sim H$ & $-\sim H$ \\
\hline & CTM-HE & ne & ne & + & - & $H$ \\
\hline & CFPN-PI & H & H & $+\sim \#$ & + & $-\sim H$ \\
\hline & CDTR-PI & $+\sim H$ & ne & $+\sim \#$ & - & H \\
\hline \multirow[t]{3}{*}{ QL } & TFLX & $+\sim H$ & $H$ & $+\sim H$ & $+\sim H$ & $H$ \\
\hline & LVFX & H & ne & $+\sim H$ & $-\sim H$ & $H$ \\
\hline & CPFX & H & $+\sim H$ & $+\sim \#$ & $+\sim \#$ & $H$ \\
\hline \multirow[t]{3}{*}{ ML } & EM & $+\sim H$ & H & $+\sim H$ & $-\sim H$ & $-\sim+$ \\
\hline & CAM & H & $H$ & $+\sim H$ & $-\sim H$ & $-\sim+$ \\
\hline & RXM & H & $H$ & $-\sim H$ & $-\sim H$ & $-\sim+$ \\
\hline \multirow[t]{3}{*}{$\mathrm{PC}$} & AMPC & ne & ne & $H$ & $H$ & $-\sim H$ \\
\hline & $\mathrm{ABPC}$ & $H$ & + & $H$ & $-\sim H$ & $-\sim H$ \\
\hline & SBTPC & ne & ne & $H$ & $H$ & $+\sim H$ \\
\hline $\mathrm{PN}$ & FRPM & H & H & $H$ & $-\sim H$ & $-\sim H$ \\
\hline $\mathrm{AG}$ & KM & $+\sim H$ & + & $+\sim H$ & $-\sim+$ & $+\sim H$ \\
\hline $\mathrm{TC}$ & MINO & $+\sim H$ & ne & $+\sim H$ & $+\sim H$ & $+\sim H$ \\
\hline ST & ST & ne & ne & ne & $+\sim H$ & H \\
\hline
\end{tabular}

- : resistant, +: weakly susceptible, + : susceptible, ne: not examined. CEP: cephem, QL: quinolone, ML: macrolide, PC: penicilline, PN: penem, AG: aminoglycoside, TC: tetracycline, ST: sulfamethoxazole trimethoprim, CCL: cefaclor, CFIX: cefixime, CFDN: cefdinir, CFTM-PI: cefteram pivoxil, CPDXPR: cefpodoxime proxetil ,CTM-HE: cefotiam hexetil, CFPN-PI: cefcapene pivoxil, CDTR-PI: cefditoren pivoxil, TFLX: tosufloxacin, LVFX: levofloxacin, CPFX: ciprofloxacin, EM: erythromycin, CAM: clarithromycin, RXM: roxithromycin, AMPC: amoxicillin, ABPC: ampicillin, SBTPC: sultamicillin, FRPM: faropenem, KM: kanamycin, MINO: minocycline.

湯 9 枚，柴胡桂枝湯・六君子湯 8 枚の順であつた. 最も併用処方の多かった組み合わせは, 補中益気湯 と CEP 系の併用であり, 次いで柴苓湯と PC 系で あつた。
2. 抗生物質の腸内細菌に対する抗菌活性 実 際に併用された抗生物質の漢方有効成分を代謝する 腸内細菌 Eubacterium 属, Bifidobacterium 属, Peptostreptococcus 属, Streptococcus 属及びE. coli 
Table 4. Combination Use of Kampo-Medicine and Bacterial Preparations

\begin{tabular}{lrccc}
\hline \hline & \multicolumn{5}{c}{ Number of prescriptions } \\
\cline { 2 - 5 } Kampo-prescription & (n) & LAC-B $^{\circledR}$ & MIYA-BM $^{\circledR}$ & BIOFERMIN $^{\circledR}$ \\
\hline Hochu-ekki-to & 46 & 38 & 5 & 3 \\
Juzen-taiho-to & 24 & 10 & 10 & 4 \\
Sairei-to & 16 & 12 & 2 & 2 \\
Daio-kanzo-to & 8 & 6 & 2 & 1 \\
Saiko-keishi-to & 7 & 6 & & \\
Sho-saiko-to & 6 & 6 & & \\
Rikkunshi-to & 3 & 3 & & 10 \\
Ninjin-to & 3 & 3 & & \\
Unsei-in & 1 & & 20 & \\
\hline Total & 114 & 84 & & \\
\hline
\end{tabular}

Table 5. Effects of Bacterial Preparations on Intestinal Bacteria Flora

\begin{tabular}{|c|c|c|}
\hline Bacterial preparations & Change in the bacteria in the intestine & Change in the enzymatic activity \\
\hline $\begin{array}{c}\text { LAC}^{-B^{\circledR}} \\
{[\text { Bifidobacterium longum }\rfloor}\end{array}$ & Bifidobacterium sp. $\quad \uparrow$ & $\beta$-glucuronidase \\
\hline $\begin{array}{c}\text { MIYA-BM }{ }^{\circledR} \\
{[\text { Clostridium butyricum }\rceil}\end{array}$ & $\begin{array}{ll}\text { Bifidobacterium } s p . & \uparrow \\
\text { Eubacterium } s p . & \uparrow\end{array}$ & no data \\
\hline $\begin{array}{c}\text { BIOFERMIN }^{\circledR} \\
{[\text { Streptococcus faecalis }\rceil}\end{array}$ & $\begin{array}{ll}\text { Streptococcus sp. } & \uparrow \\
\text { Bifidobacterium sp. } & \uparrow \\
\text { E. coli } & \downarrow\end{array}$ & no data \\
\hline
\end{tabular}

に対する抗菌活性を Table 3 に示した。ほとんどの 抗生物質は腸内細菌に対して抗菌活性を示したが, 抗生物質の種類によっては耐性を示すものもあった.

Eubacterium 属に対して, ほとんどの抗生物質は強 い抗菌活性を示したが, cefteram pivoxil には耐性 を示すデータもあった. 同様に, Peptostreptococcus 属に対して cefaclor 及び roxithromycin は耐性 を示すデータもあった。また，Streptococcus 属に 対する CEP 系, ML 系及び AG 系, E. coli に対す る ML 系など特定の系統の抗生物質が耐性を示す 傾向も認められた.このように, 抗生物質の種類に よって抗菌活性は異なり, さらに, 同じ作用機序の 薬剂でも抗菌活性は異なるものもあった。

3. 漢方薬と生菌製剤の併用実態 調査処方箋 1199 枚（患者数 308 名）のうち，114 枚（10\%）に 生菌製剂が併用処方されていた。 その内訳は，ラッ クビー ${ }^{\circledR 8} 84$ 枚, ミヤ $\mathrm{BM}^{{ }^{\circledR}} 20$ 枚, ビオフェルミン ${ }^{\circledR} 10$ 枚であった（Table 4). 生菌製剤と最も多く併用さ れた漢方薬は, 補中益気湯 46 枚であり, 次いで,
十全大補湯 24 枚, 柴苓湯 16 枚などが生菌製剤と併 用されていた. 最も併用処方の多かった組み合わせ は, 補中益気湯とラックビー ${ }^{\circledR} 38$ 枚, 次いで柴苓 湯とラックビー ${ }^{\circledR} 12$ 枚であった。

4. 生菌製剤の腸内細菌に与える影響 実際に 併用された生菌製剂が，漢方有効成分を代謝する腸 内細菌に与える影響を Table 5 に示した。ラック ビーツ Bifidobacterium longum 製剂であり，連続 投与によって, 腸内細菌叢における Bifidobacteri-

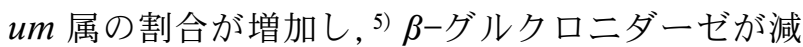
少するとの報告があった。 ${ }^{5)}$ ミ $\mathrm{BM}^{\circledR}$ は Clostridium butyricum 製剂であり, 連続投与によって Bifidobacterium 属, Eubacterium 属の増加をもたら す.6,7) ビオフェルミンは Streptococcus faecalis 製 剂であり, Bifidobacterium 属, Streptococcus 属が 増加し, E. coli は減少する. ${ }^{8)}$

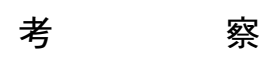

今回の処方調査から, 実際に，7-10\%の割合で 
漢方薬に抗生物質又は生菌製剤が併用処方されてい ることが判明した．文献調査から，抗生物質及び生 菌製剂は，それらの種類によって腸内細菌に与える 影響が異なると予測され，併用による漢方有効成分 の代謝に与える影響も異なると予測された。

ほとんどの抗生物質は, 腸内細菌に対して抗菌活 性を示すことが多く, 併用により漢方有効成分の代 謝が低下すると考えられた。一方，抗生物質の種類 によっては, 腸内細菌に与える影響が他の抗生物質 と比較して少ないと予測されるものもあった．例え ば，Streptococcus 属に対して CEP 系及び ML 系， E. coli に対して ML 系は耐性を示す傾向があり, 黄芩を含む漢方薬との併用において, BL 代謝に与 える影響は他の抗生物質と比較して少ないと予測さ れた。

生菌製剤のラックビー ${ }^{\circledR}, ミ ヤ ~ \mathrm{BM}^{\circledR}$, ビオフェル ミン®，連続投与によって，Bifidobacterium 属の 増加をもたらす. $5,7,8)$ したがって, 大黄甘草湯や大 柴胡湯のような大黄含有漢方薬との併用において, SEN 代謝を促進すると予測される。また，ミヤ $\mathrm{BM}^{\circledR}$ は連続投与によって Eubacterium 属が増加す る6)ので, 十全大補湯や柴苓湯のような甘草含有漢 方薬との併用において，GL 代謝の増加が予測され

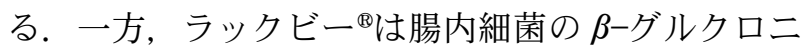
ダーゼ量を低下させるとの報告 ${ }^{5)}$ があるため, 柴胡 桂枝湯や小柴胡湯のような黄芩含有漢方薬との併用 において BL 代謝の減少をもたらすと予測される.

GL, BL 及び SEN の代謝への予測される影響を 併用薬（抗生物質及び生菌製剂）の組み合わせで示 すと Table 6 になる. 今回の処方調査において, 補 中益気湯と CEP 系の併用処方が多かったが，これ らの併用により補中益気湯中の GL 代謝が減少する と考えられた。また，生菌製剂との併用において は，柴苓湯とラックビーツの併用処方が多かった が，ラックビーツは $\beta$-グルクロニダーゼ量を低下さ せるとの報告5)があるため, 併用により BL 代謝が 減少すると考えられた.

以上の結果から，漢方有効成分の代謝に影響する と考えられる抗生物質や生菌製剂の併用実態が明ら かになった。併用処方された抗生物質や生菌製剤は その種類によって有効成分の代謝に及ぼす影響が異 なることが予想された。しかし，これらの予測は， あくまでも抗生物質の抗菌活性から求めたものであ
Table 6. Effects of Antibiotics and Bacterial Preparations on the Metabolism of Active Ingredients in the Intestinal Bacteria Flora

\begin{tabular}{lccc}
\hline \hline \multirow{2}{*}{$\begin{array}{c}\text { Active } \\
\text { ingredients }\end{array}$} & \multicolumn{2}{c}{ Metabolism of active ingredients } \\
\cline { 2 - 4 } Glycyrrhizin & Increase $^{\text {MIYA-BM }}{ }^{\circledR}$ & Decrease & No change \\
\hline \multirow{3}{*}{ Baicalin } & & PC, PN, AG & \\
& & TC & \\
& & QL, PC, PN & CEP, ML \\
Sennoside & & AG, TC, ST & \\
& & LAC-B & \\
& LAC-B $^{\circledR}$ & CEP, QL, ML & \\
& MIYA-BM $^{\circledR}$ & PC, PN, AG & \\
& BIOFERMIN $^{\circledR}$ & TC \\
\hline
\end{tabular}

り，実際に抗生物質を服用した場合の腸内細菌叢の 変動などを実証したものではない。生菌製剤の影響 についても，腸内細菌叢が変化するにはある程度の 連続投与が必要であることが報告5)されており, 併 用開始後すぐに相互作用が成立する可能性は低い.

このように, 実際の併用効果については, 処方実態 に合わせた投与試験により検証する必要があると考 え，検討を進めている。

\section{REFERENCES}

1) "Gastro-Intestinal Ecology," ed. by Kobashi K., Toyama Medical and Pharmaceutical University, Toyama, 1994.

2) "Chonai flora to kenko," ed. by Mitsuoka T., Gakkai Center Kansai, Osaka, 1998.

3) Nanri S., Kansenshogaku Zasshi, 54, 766-788 (1980).

4) Akita H., Kansenshogaku Zasshi, 56, 12031215 (1982).

5) Benno Y., Mitsuoka T., Microbiol. Immunol., 36, 683-694 (1992).

6) Okamoto T., Sasaki M., Araki Y., Fukuda M., Kimura T., Myojo S., Tsujikawa T., Fujiyama Y., Bamba T., Kusunoki M., Digestion and Absorption, 19, 65-68 (1996).

7) Zhang D., Dong X., Bao Y., Chin. J. Gastroenterol, 3, 82-84 (1998).

8) Katsumata S., Shonikagakkai Zasshi, 58, 893968 (1953).

9) Kimura Y., Yoshida I., Higashiyama I., Sasaki S., Chemotherapy, 48, 585-609 (2000). 
10) Yoshida I., Higashiyama I., Kimura Y., Sasaki S., Chemotherapy, 48, 610-632 (2000).

11) Sasaki J., Sakamoto H., Ohta Y., Aoki T., Karakida K., Kimura Y., Hasegawa J., Katayama I., Shiiki K., Naitoh H., Yamane N., Takakura J., Satoh T., Yamaguchi M., Abe A., Michi K., Ohno K., Matsui Y., Nakamura A., Matsuda C., Tabei Y., Nagumo M., Manabe M., Kamijou R., Osone Y., Mikami S., Shirai T., Ishibashi K., Nagashima H., Kawachi S., Kawase Y., Shinagawa T., Katoh H., Yamamoto T., Okano H., Morita S., Tsunokuma M., Fukutake Y., Minato S., Oral Ther. Pharmacol., 15, 90-105 (1996).

12) Nagahira K., Kato N., Tanaka K., Watanabe K., Ueno K., Chemotherapy, 42, S-1, 38-50 (1994).

13) Sasaki J., Morishima T., Takai H., Ikejima K., Shiiki K., Kanno K., Kaneko A., Sakamoto H., Narita Y., Ozeki H., Satoh T., Takada C., Michi K., Tashiro T., Nagumo M., Manabe M., Osone Y., Ishibashi K., Yamamoto H., Kawachi S., Koga I., Yamamoto T., Kanoh Y., Minato S., Oral Ther. Pharmacol., 12, 17-32 (1993).

14) Komatsu Y., Nagata H., Motokawa K., Kameda Y., Nomura K., Higashiyama I., Doi M., Yoshida T., Chemotherapy, 41, S-1, 7793 (1993).

15) Deguchi K., Yokota N., Koguchi M., Suzuki Y., Fukayama S., Ishihara R., Oda S., Jpn. J. Antibiot., 47, 129-142 (1994).

16) Nishino T., Watanabe Y., Otsuki M., Chemotherapy, 41, S-1, 50-76 (1993).

17) Nishino T., Tanaka M., Aono Y., Iwai T., Otsuki M., Chemotherapy, 40, S-3, 36-50 (1992).

18) Watanabe K., Kato N., Muto Y., Bando K., Ueno K., Chemotherapy, 40, S-3, 57-63 (1992).

19) Goto S., Miyazaki Y., Miyazaki S., Tsuji A., Kaneko Y., Chemotherapy, 40, S-2, 16-29 (1992).

20) Watanabe K., Muto Y., Bando K., Kato N., Tanaka Y., Ueno K., Chemotherapy, 40, S-2, 30-36 (1992).

21) Kaneko A., Shiiki K., Sakamoto H., Satoh T., Michi K., Osone Y., Konnai T., Yamamoto T., Hattori T., Sugimura M., Fujii N.,
Deguchi K., Sasaki J., Oral Ther. Pharmacol., 9, 113-122 (1990).

22) Iwata S., Yamada K., Kin Y., Yokota T., Kusumoto H., Sato Y., Akita H., Nanri S., Oikawa T., Sunakawa K., Ichihashi Y., Jpn. J. Antibiot., 42, 1761-1779 (1989) .

23 ) Inoue E., Inoue M., Mitsuhashi S., Chemotherapy, 37, S-2, 1-15 (1989).

24) Kato N., Muto Y., Watanabe K., Ueno K., Chemotherapy, 37, S-2, 65-76 (1989).

25) Nishino T., Otsuki M., Matsuda H., Tanino T., Chemotherapy, 36, S-6, 59-79 (1988).

26) Goto S., Muto Y., Ogawa M., Kaneko Y., Kuwahara S., Chemotherapy, 36, S-9, 36-58 (1988).

27) Kato N., Muto Y., Watanabe K., Ueno K., Chemotherapy, 36, S-9, 59-67 (1988).

28) Ono T., Numata K., Inoue M., Mihashi S., Chemotherapy, 36, S-3, 1-34 (1988).

29) Kato N., Sawamura H., Sawa K., Watanabe K., Ueno K., Chemotherapy, 36, S-3, 71-81 (1988).

30) Tsuboi Y., Inoue M., Mitsuhashi S., Chemotherapy, 36, S-4, 1-17 (1988).

31) Kato N., Miyauchi M., Sawamura N., Watanabe K., Ueno K., Chemotherapy, 36, S4, 65-75 (1988).

32) Masaki M., Inoue $Y$. , Masumoto H., Masuyama Y., Dohtsu Y., Miyazaki T., Koga H., Suyama N., Hayashi T., Kawano S., Yamaguchi E., Hirota M., Hara K., Hirakata Y., Mochida C., Sugawara K., Usui T., Chemotherapy, 36, S-4, 421-437 (1988).

33) Sawa K., Kanno H., Aoki M., Kobayashi T., Watanabe K., Ueno K., Chemotherapy, 34, S2, 34-43 (1986).

34) Saikawa I., Hotta T., Watanabe Y., Hukuoka Y., Yotsuji A., Minami S., Yamashiro Y., Araki H., Ogake N., Chemotherapy, 34, S-2, 66-84 (1986).

35) Nishino T., Obana Y., Goto K., Kuniyasu T., Yano T., Chemotherapy, 33, S-6, 75-96 (1985).

36) Uemura T., Tawara S., Sakamoto H., Hirose T., Watanabe Y., Mine Y., Goto S., Nishida M., Kuwahara S., Chemotherapy, 33, S-6, 109-122 (1985).

37) Shimada K., Adachi K., Tanaka K., Kamijoh H., Sasaki M., Hatakeyama T., Inamatsu T., 
Urayama K., Chemotherapy, 31, 835-841 (1983) .

38) Utsuka Y., Shishido H., J. Med. Pharmaceut. Sci., 7, 333-339 (1982).

39) Sawatari K., Mochida C., Iori F., Hayashi A., Nasu M., Jpn. J. Antibiot., 33, 87-96 (1980) .

40) Nishino T., Kubota M., Chemotherapy, 27, S7, 38-58 (1979)

41) Shimizu T., Matsuda M., Kiso to Rinsho, 11, 1553-1563 (1977).

42) Nakazawa S., Kitanaka H., Otsuki M., Hukui M., Chemotherapy, 21, 1375-1382 (1973).

43) Kobayashi M., Takami T., Mitsuda T., Teraguchi K., Jpn. J. Antibiot., 25, 283-287 (1972) .

44) Sutherland R., Rolinson G., Antimicrob. Agents Chemother., 10, 411-415 (1970).

45) “Kokinzai Handbook," ed. by Ohno T.,
Sekai Hoken Tsushin Co., Ltd., Osaka, 1992, pp. 1-163.

46) Hujita H., Hokkaido Shikaishi Kaishi, 53, 283 -294 (1998).

47) “Antibiotics in Laboratory Medicine," ed. by Lorian V., Williams and Wilkins, London, 1980, pp. 635-687.

48) Chimura T., Jpn. J. Antibiot., 44, 538-542 (1991).

49) Macgowan A. P., Bowker K. E., Holt H. A., Wootton M., Reeves D. S., J. Antimicrob. Chemother., 40, 503-509 (1997).

50) Olsvik B., Hansen B. F., Tenover F. C., Olsen I., J. Clin. Periodontol., 22, 391-396 (1995).

51) "Fundamental and Clinical Investigations on Disc Sensitivity Testing,' ed. by Kanazawa Y., Showa Yakuhin Kako Co., Ltd., Tokyo, 1994, p. 240. 